\title{
AS RUGOSIDADES DO CIBERESPAÇO: um contributo teórico aos estudos dos web espaços informacionais
}

\author{
Ricardo Medeiros Pimenta*
}

RESUMO Apresenta uma contribuição à área da Ciência da Informação, em sua dimensão teórica, ao trabalhar conceitos do geógrafo Milton Santos como elementos norteadores para uma análise das infraestruturas físicas e tecnológicas que compõem o que intitulo como web espaços informacionais. Balizado também em conceitos do filósofo Gilbert Simondon, propõe-se identificar as estruturas e objetos técnicos que compõem estes espaços em seu processo de concretização, reconhecendo nestes mesmos, práticas recorrentes de um cenário global marcado pela concentração de capital e conhecimento científico tecnológico. $\mathrm{O}$ artigo abre, com isso, a proposição de que as formas de visibilidade e acesso da informação nos web espaços informacionais constituem-se a priori como rugosidades de uma estrutura já existente apesar das inovações quanto aos objetos, plataformas e sistemas informacionais em constante ebulição.

Palavras-chave: Ciberespaço. Internet. Informação. Rugosidade. Milton Santos.

* Doutor em Memória Social pela Universidade Federal do Estado do Rio de Janeiro, Brasil. Estágio doutoral na École des Hautes Études en Sciences Sociales, França. Docente permanente do Programa de Pós-Graduação em Ciência da Informação. Pesquisador Adjunto do Instituto Brasileiro de Informação em Ciência e Tecnologia do Ministério da Ciência, Tecnologia e Inovação, Brasil.

E-mail: ricardo.pimenta@gmail.com.

\section{INTRODUÇÃO}

$\checkmark$ $m$ pleno século XXI o avanço das tecnologias da informação e da comunicação, juntamente com sua exploração e apropriação cultural tornou urgente, e sempre atual devido a plasticidade e constância inovadora dos usos das plataformas digitais, um olhar reflexivo permanente sobre tal cenário cuja produção, circulação e acesso da informação tornara-se por vezes até simulacro das políticas públicas e das disputas no tecido social pela informação e conhecimento.

A interrogação de Pinheiro (2012, p. 64), concernente à mudança de suportes ou de regimes sempre que a cada momento de mudança do sistema de escrita, assegurada a mudança dos "sistemas de representação de mundo" (JEANNERET, 2008) traz à tona uma discussão dupla: por um lado, uma discussão acerca da inovação, esta bem respondida pela autora; e por outro, sobre as permanências discursivas, políticas e socioculturais, e suas reproduções em cenário aparentemente novo. Esta última é a que buscaremos contribuir sob a luz de um teórico dos espaços: Milton Santos. Em "a natureza do espaço" Santos (2006) aponta para o conceito de meio técnico-científico informacional enquanto configuração espacial marcadamente iniciada em meados do século XX, após a segunda guerra mundial, e que representaria um novo momento de produção, utilização e funcionamento do espaço.

Ao cabo desse esclarecimento preliminar este texto configura-se como lugar propositivo de "co-habitação" de conceitos como os de "regimes de informação" (GONZÁLEZ DE GÓMEZ, 2012) e de "meios técnico-científicos" (SANTOS, 2006) para refletir as implicações do ciberespaço e suas dimensões político-discursivas e técnicofísicas como espaços de ordem equivalente e que delineiam as "formas" possíveis da paisagem informacional digital contemporânea. Nesse 
sentido, concernente ao ciberespaço, há não tão somente o espaço acreditado "livre", de criação e colaborativo; vetor de uma "inteligência coletiva" (LÉVY, 2003) democrática e inclusiva.

Há para além das "fronteiras" e marcações que o qualifica, uma origem, um terreno; um "chão" do qual esta mesma reprodução do modelo utópico de "aldeia global" é devedora pois está ainda hoje a ele conectado e, portanto, ancorado. $\mathrm{Ou}$ seja, diferente do sentido "aberto" e completamente "desterritorializado" do ciberespaço mesmo em sua gênese, como propõe Lazzarin, Azevedo Netto e Sousa (2015, p. 24), a partir da perspectiva de Santos, mesmo o ciberespaço a priori desterritorializado, traz consigo em seu próprio nomos informacional, traços, ransos ou "rugosidades" características dos regimes informacionais e das formas de dominação inerentes à sociedade da informação na qual ele se encontra.

Ou seja, protocolos; formas de acesso e navegabilidade; o próprio aspecto da surface web e da deep web; os objetos técnicos pelos quais unicamente temos acesso a este território virtual, mas que, por vezes, já redefine o real; suas tecnopolíticas de vigilância instauradas no ambiente digital; sua estrutura física de cabos para a tráfego de dados e informações. Todos estes aspectos já apontam para o que Milton Santos chamará de "rugosidades".

\begin{abstract}
Chamemos rugosidade ao que fica do passado como forma, espaço construído, paisagem, o que resta do processo de supressão, acumulação, superposição, com que as coisas se substituem e acumulam em todos os lugares. As rugosidades se apresentam como formas isoladas ou como arranjos. É dessa forma que elas são uma parte desse espaço -fator. Ainda que sem tradução imediata, as rugosidades nos trazem os restos de divisões do trabalho já passadas (todas as escalas da divisão do trabalho), os restos dos tipos de capital utilizados e suas combinações técnicas e sociais com o trabalho. (SANTOS, 2006, p. 92).
\end{abstract}

No todo, este artigo é parte de uma pesquisa sobre a memória e o esquecimento na era digital, encerrada em dezembro de 2015, que busca a construção de uma teoria ${ }^{1}$; assim como

\footnotetext{
Pesquisa "dimensões tecnopolíticas do esquecimento: usos e abusos da memória na era digital" financiada pelo CNPq. A pesquisa, encerrada em dezembro de 2015, estava em andamento durante a escrita deste artigo.
}

dá continuidade às reflexões em estágio inicial sobre a visibilidade informacional ${ }^{2}$ tendo como perspectiva neste trabalho a infraestrutura que promove os meios técnicos para tal visibilidade ou mesmo seu controle. Em sua dimensão espacial, tal era é, portanto, representada e constantemente redefinida na medida em que as espacialidades digitais e seus territórios vão se atualizando frente ao avanço tecnológico a despeito do "não tão avanço" dos regimes políticos, econômicos e culturais que ainda as dirige.

\subsection{Breve retrospectiva de um recente velho cenário}

Os últimos 25 anos foram marcados pelo aparecimento e desenvolvimento do ciberespaço e da internet enquanto sua dimensão mais popular e de mercado. Sua cartografia é composta por quilômetros de cabos submarinos e terrestres, que ligam países, conectados a hosts e servidores capazes de redistribuir via protocolos o fluxo de dados em escala não restritiva. Nesta dinâmica info-comunicacional as mídias vêm se tornando cada vez mais convergentes nos últimos anos; uma vez que computadores e demais aparelhos eletrônicos capazes de se conectarem a este espaço de trânsito de dados e informações digitais se tornam mais velozes, mais baratos e mais comuns (RYAN, 2010, p. 5660) em uma cultura digital global.

Um campo vasto onde suas fronteiras se confundem entre camadas, protocolos de acesso, endereços e linguagens; o ciberespaço ainda se mostra como um espaço parcialmente indeterminado (LÉVY, 2003, p. 104), sempre permeado pelas informações circulantes e/ou armazenadas (RABAÇA; BARBOSA, 2001) faz-se, portanto, local de disponibilização de informações (MONTEIRO, 2007) mediadas pelas tecnologias digitais e pelas práticas por meio delas materializadas e representadas no âmbito da rede mundial de computadores: a internet.

Estas tecnologias propiciaram a consolidação de um espaço novo de sociabilidade cujas práticas cotidianas egressas do mundo virtual acabam por redefinir as práticas do mundo real em larga escala. Nesse sentido, o

2 Pesquisa em andamento relacionada à Bolsa de Produtividade PQ-2 do CNPq. 
ciberespaço é um simulacro (BRAUDILLARD, 1991). Um espaço de camadas, contornos e territórios diversos e móveis, jamais passíveis de serem "capturados" em toda sua complexidade no mundo real, pois o extrapola. Nesse sentido, o vasto campo informacional e comunicacional da web configura-se como um "mapa aberto" (BEY, 2001) no qual aquele próprio vem a ser uma faceta importante da "máquina de guerra" frente os dispositivos de dominação e controle característicos das políticas globais de informação (BRAMAN, 2004), estas responsáveis pelo que Bey denomina o "fechamento do mapa", criando territórios. Paradoxalmente é essa mesma máquina de guerra, expressão criativa e de resistência característica do "regime de informação" vigente uma vez que ela só existe por haver, portanto, o seu contrário.

Nesse sentido, o que chamamos de contrário é justamente tudo aquilo que produz o território no qual a própria internet, como a conhecemos hoje, foi edificada. Esta, apesar de ser um simulacro, traz em si as "rugosidades" características de sua realidade predecessora. Neste texto, buscamos refletir sobre esta afirmação na qual, fazendo uso de um dos conceitos de Milton Santos, compreendemos que as rugosidades presentes no ciberespaço, no território da internet, apesar de todos os novos recursos tecnológicos atuais e que de fato criam e mantém este novo espaço, ainda contribuem fortemente para o "tom" das relações sociais, políticas e econômicas ali instauradas no espaço virtual.

Para Santos (2006, p. 25), as rugosidades são similares aos "reverse salients" de que trata Hughes (1980) e às quais Joerges (1988) faz menção. Marcas que denotam irregularidades advindas de um processo sócio-histórico no âmbito do desenvolvimento tecnológico, juntamente com sua técnica, em um dado espaço ou território.

Neste sentido, os são igualmente os novos espaços criados pelo homem por meio das novas tecnologias de informação e comunicação (TIC). Espaços de câmbios culturais e socioeconômicos. E que se tornaram os simulacros do século XXI.

\section{AS IDIOSSINCRASIAS DO ESPAÇO $W E B$}

A world wide web possibilitou o compartilhamento de bens culturais heterogêneos por atores igualmente diversos e levou a uma parcela da população mundial grande liberdade de acesso às informações, ou pelo menos parte delas, em um fluxo comunicacional dinâmico e ininterrupto. Tal fenômeno não deixou de se tornar campo de atuação exploratória pela indústria cultural, apesar de ter constituído novo campo de batalha contra as explorações da política de copyright por meio de inúmeras iniciativas de compartilhamento de conteúdos informacionais por usuários da rede. É fato que a internet levou acesso aos que podem pagar por ela, ofertando ao público que nela navega, junto aos novos objetos de consumo-comunicação (LIPOVETSKY, 2007, p. 32), os meios de compensação frente ao novo território de controle informacional pelo consumo de mercadorias e experiências.

Grosso modo para além das possibilidades emancipatórias, democráticas, deliberativas e de ação presentes no território da internet, precisamos não ignorar o fato de que todo este "simulacro", que certamente influencia o espaço físico social, continua ancorado por um sistema nada virtual e, portanto, muito real, de cabos submarinos e grandes servidores que por si só continuam a evidenciar uma velha forma de dominação socioeconômica e de controle: do monopólio dos bens materiais, de tecnologia e sua infraestrutura necessários à circulação da informação em escala global e, portanto, representantes de uma economia política infocomunicacional planetária.

Na figura 1 é possível identificar no mapa ali representado a quantidade de cabos submarinos existentes e, por conseguinte, averiguar uma maior concentração desses mesmos cabos, responsáveis pelo trafego da internet e pela continuidade do fluxo informacional no âmbito das tecnologias de informação e comunicação (TIC), no hemisfério norte. Da mesma maneira, os cabos presentes no hemisfério sul são de propriedade das mesmas corporações proprietárias daqueles do hemisfério norte. 
Figura 1: Mapa de cabos submarinos.

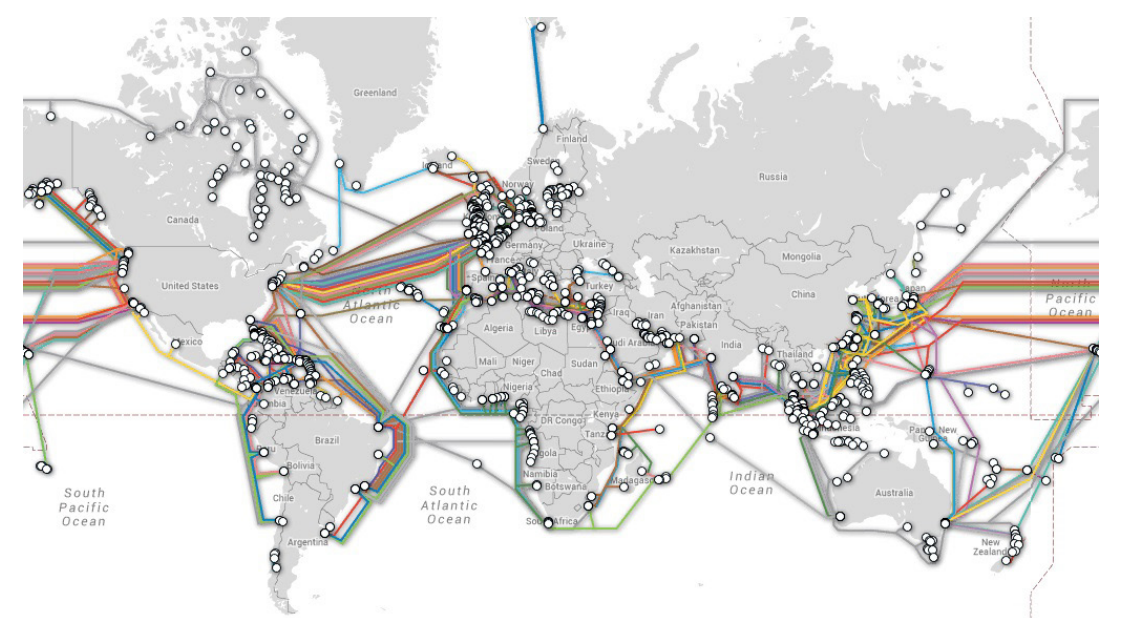

Fonte: TeleGeography / Huawei Marine Networks. <http://www.submarinecablemap.com/\#/>. Acesso 06 nov. 2015.

Esta subordinação, de proporções históricas reside principalmente no acúmulo de recursos militares e econômicos nos estados do hemisfério norte e tornou-se um conceito mais disseminado a partir do início dos anos 1990 após a queda do muro de Berlim e com ele a polaridade capitalismo $\mathrm{x}$ socialismo (TODARO; SMITH, 2012). Hoje, cabe afirmar que a tecnologia da informação tem se tornado um novo insumo deste já não tão novo cenário dialético entre norte e sul; onde se exploram da produção em tecnologia à sua aplicabilidade e uso por parte da população mundial, em especial aquela localizada no hemisfério sul.

No entorno da América do Sul, na figura 2, destacamos um dos cabos submarinos cujo proprietário é a empresa espanhola Telefonica. Este destaque, a titulo de exemplo, possibilita afirmarmos que entre tantos outros cabos que compõe a base estrutural do que conhecemos como internet, vivemos ainda um ranço no tocante à subordinação do capital global sul para com o norte. Afinal, ainda em 2015, a América do Sul continua grosso modo "colonizada", agora por uma corporação espanhola do ramo de comunicação.

Figura 2: Cabo submarino South America 1 (Sam-1).

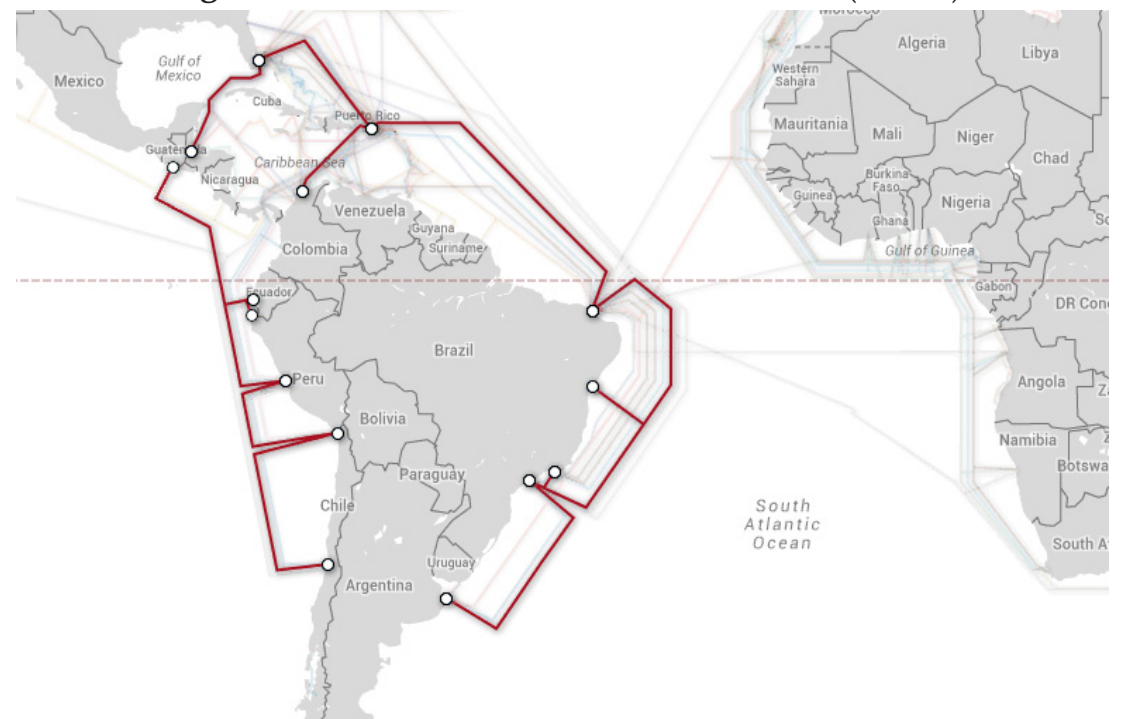

Fonte: TeleGeography / Huawei Marine Networks.

<http:/ / www.submarinecablemap.com/\#/>. Acesso 22 nov. 2015 
A informação, seu tráfego e uso, tornou-se o novo capital do século XX e XXI; relação esta proposta aqui e bem fundamentada em análises de como as de Lopes (2008) e Marques (2016). Um capital disputado em um cenário marcado, em perspectiva histórica, pela exploração nortesul.
Não obstante, mesmo se cogitarmos as "potencias emancipadoras" advindas do uso da internet em escala horizontal, como exemplificada aqui na figura 3 , vale lembrar que o domínio continua nas mãos de grandes corporações internacionais. Este é o exemplo do cabo submarino South Atlantic Express (SAEx), de propriedade da empresa canadense Simplcom.

Figura 3: Cabo submarino South Atlantic Express (SAEx).

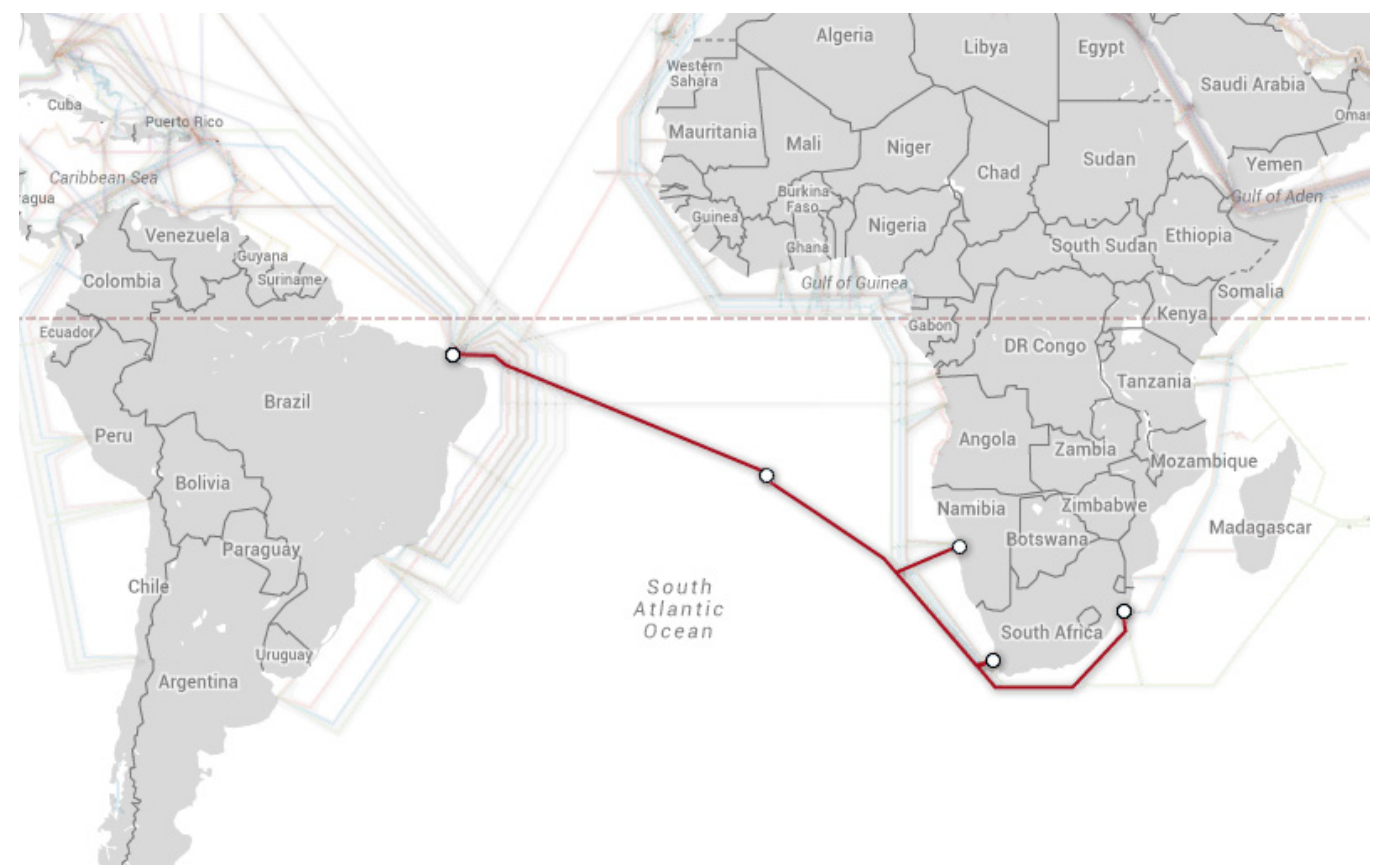

Fonte: TeleGeography / Huawei Marine Networks. <http://www.submarinecablemap.com/\#/>. Acesso 22 nov. 2015.

Na grande maioria dos casos a participação mista de empresas diversas ainda sugere que a disputa pela hegemonia da infraestrutura que compõe o território infocomunicacional global tem como maiores personagens a iniciativa privada internacional oriunda do hemisfério norte. Afinal, é este hemisfério que aponta como o maior consumidor de energia e de bens naturais, provocando um desequilíbrio e, portanto, uma clara desregulação da distribuição de capital e dessimetria do mercado.

Segundo as Nações Unidas (Informe sobre o Desenvolvimento Humano, 1998), há um consumo desigual no mundo, onde $80 \%$ da população mundial (que corresponde aos países menos desenvolvidos, principalmente os países pobres do hemisfério sul) utiliza $20 \%$ dos recursos naturais. São 2,8 bilhões de pessoas que mal sobrevivem com menos de US\$ 2 diários. Já os países desenvolvidos, com somente $20 \%$ da população mundial (principalmente os países do hemisfério norte), consomem $80 \%$ dos recursos naturais e energia do planeta e produzem mais de $80 \%$ da poluição e da degradação dos ecossistemas. Essa mesma fonte informa que os países ricos consumiam, na década de 1990 , $85 \%$ do alumínio e químicos sintéticos, $80 \%$ do papel, ferro e aço, $80 \%$ da energia comercial, $75 \%$ da madeira, $65 \%$ da carne, dos pesticidas e do cimento, $50 \%$ dos peixes e grãos e $40 \%$ da água doce. Segundo a Organização das Nações Unidas para a Educação, a Ciência e a Cultura, uma criança nascida em um país industrializado contribuirá 
mais para o consumo e poluição do que 30 a 50 crianças nascidas em países em desenvolvimento. (CORTEZ; ORTIGOZA, 2009, p.44).

O consumo desigual em âmbito global e sua exploração são tão somente uma face da assimetria do acesso e uso de recursos sejam eles naturais ou mesmo tecnológicos. Tal constatação nos convida a revisitar a célebre afirmação de McLuhan (2011): “o meio é a mensagem". Afinal, toda a potência da internet é devedora ainda de uma infraestrutura tecnopolítica e econômica igualmente correspondente à assimetria do consumo e exploração de recursos no cenário global.

Estes mesmos cabos submarinos, como vimos nas figuras 1, 2 e 3, conectam os servidores e data centers estrategicamente dispostos globalmente e a partir dessa demarcação espacial, conectam-se os computadores, notebooks e smartphones de todo o mundo na rede mundial de computadores. Estes cabos, contudo, têm seus "donos". Os mesmos que historicamente contribuíram para a concentração de capital em alguns países do hemisfério norte. A informação jamais foi tão abundante e de veloz acesso como hoje, graças ao território digital conhecido como internet.

Ademais, ao identificar a informação como novo insumo para as forças produtivas de um mundo globalizado, Freire (2006, p. 58) nos sinaliza que este mundo seria a materialização, portanto, de um paradigma. Contudo, tal materialização, ou possível "concretização" (SIMONDON, 1989) do ponto de vista simondoniano, não faz mudar as estruturas fundamentais das formas de poder inerentes à geografia infocomunicacional que rege o acesso e consumo de bens tecnológicos no planeta. Não obstante, é igualmente óbvio que seja a partir dos usos da internet por seus atores sociais e políticos diversos que haja possibilidades em levar a xeque sua própria estrutura original de dominação. A dúvida, entretanto, reside na questão: a "criatura" poderá dominar o criador?

Apesar de parecer ainda difícil, não é impossível. Com efeito, a aceleração das ferramentas tecnológicas eletrônicas e virtuais possibilitam hoje não somente o acesso constante, em grande volume e velocidade de informação, mas a viabilidade do que conhecemos como globalização apesar de a mesma não significar a extinção de fronteiras e formas de dominação e exploração de recursos naturais, tecnológicos, intelectuais e simbólicos na contemporaneidade.

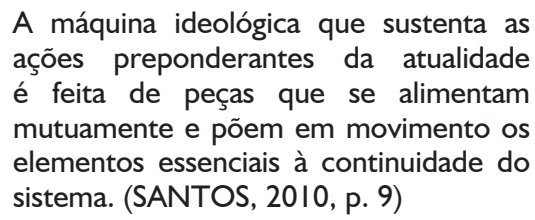

A máquina ideológica que sustenta as ações preponderantes da atualidade é feita de peças que se alimentam mutuamente e põem em movimento os elementos essenciais à continuidade do sistema. (SANTOS, 2010, p. 9)

Em concordância com o pensamento de Milton Santos, consideramos oportuno considerar que a geografia da dominação e do controle das estruturas informacionais, de sua materialidade e representatividade, não muda completamente. Apenas se transforma de maneira a manter-se centro e jamais tornar-se periférico.

Por isso é plausível considerar também que, no cenário atual, as diásporas socioeconômicas continuem. Ademais, é igualmente visível que novas fronteiras também se formaram enquanto outras velhas se mantiveram muito estáveis. $\mathrm{O}$ acesso à informação, por exemplo, com o advento da internet claramente se expandiu, mas tal fenômeno não deveria escamotear uma realidade de mais de 1,2 bilhões de pessoas, segundo relatório da ONU (UN FOUNDATION, 2013), sem acesso à energia elétrica no mundo. Fato este que aponta uma permanência de desigualdades de base no cenário mundial.

Apesar de termos diminuído os quilômetros de distância quando o assunto é comunicação e informação, não está garantido que tal experiência esteja disponível para toda a população mundial. E, nesse caso, desconsiderar tais diferenças reais é impor ao real a política de um simulacro que se propõe substitutiva ao real ou complementar a ele. É, portanto, não nos importarmos ou surpreender com a alteridade produto de uma histórica práxis da exclusão em proporções transnacionais.

Tal caso exemplifica bem o que se afirma aqui: o emprego de novas formas de proximidade, e sua respectiva relação com o espaço, criou um simulacro sem igual onde as estruturas sociais, culturais e econômicas ganharam novos contornos apesar de estabelecerem as mesmas dinâmicas de dominação entre as classes sociais. Contudo, um questionamento ainda persiste: quem domina o ciberespaço? Quem domina a internet? 
A resposta continua a ser preenchida pelos nomes de grandes empresas, corporações, e seus respectivos acionistas. Que por sua vez continuam a representar a acumulação de capital assimétrica em termos globais. Como apontado por Mounier (2006, pp. 127-129), com a revolução digital uma nova guerra por territórios se deu tendo os recursos tecnológicos e informacionais como os capitais em disputa. Empresas como Microsoft, Apple, Samsung, AOL, Facebook, Twitter, Youtube, entre outras, e seus respectivos acionistas majoritários, com a devida licença aos anacronismos, tornaram-se os novos "senhores feudais" de um espaço jamais cogitado em seu valor, em seu potencial e em suas dimensões.

Mais uma vez, na perspectiva do pensamento de Santos (2010), o final do século XX foi emblemático por promover no que ele chama de ápice do sistema capitalista, uma "fusão" dos campos de produção, finanças e informação. A comunicação em tempo real via canais digitais estabeleceu um incremento à economia, ao mercado de trabalho e, obviamente, ao consumo. Estabeleceu também uma maior aproximação entre os atores sociais possuidores das competências necessárias para fazer uso dessas novas tecnologias; sabendo-se que pouco se fala dos excluídos digitais, parcela essa ainda muito maior do que aquela que possui acesso à internet.

Atualmente, em relatório da Organização das Nações Unidas (ONU), ligado à União Internacional de Telecomunicações (ITU, 2015), a estimativa de pessoas que não acessam a internet é de 4 bilhões de pessoas, cerca de $57 \%$ da população mundial. Se considerarmos o número dos que acessam, cabe apontar que a acesso não pressupõe bom uso dos mecanismos info-comunicacionais e, portanto, o número de pessoas que mais claramente se beneficiam do uso da internet e das informações ali disponibilizadas, além de sua potência comunicativa, é bem menor do que o resultado divulgado pelo documento da ONU.

\footnotetext{
Falamos de duas coisas indissociáveis: a existência e expansão comercial de dispositivos com determinadas características, nomeadamente a infraestrutura de base (a rede eléctrica e telemática), e a capacidade instrumental para usá-los. Simplificando temos um computador com acesso à internet
}

e pessoas habilitadas a usar este equipamento com grau comprovado de eficiência. Alfabetização informática (ou digital), literacia digital ou inclusão digital são expressões sinónimas quando significam exactamente a situação descrita. E as pessoas dotadas dessas competências ou habilidades entram na categoria de alfabetizadas digitais, info-incluídas ou de nativos digitais (born digital). Estes, em rigor, são os nascidos na Era Digital (após 1980) com acesso às tecnologias digitais em rede $\mathrm{e}$ dotados de sólida formação no uso de computadores. (SILVA, 2008, p. 29-30).

O mundo desenvolve-se tecnologicamente, mas os territórios advindos desse desenvolvimento, ou mesmo aqueles legitimados apesar dele, continuam os mesmos apesar de suas diferenças.

\section{[...] o aumento do uso de novas tecnologias e suas possibilidades interativas [...] já aumentaram a já existente divisão entre aqueles que podem ter e fazer bom uso delas e aqueles excluídos pelas barreiras culturais financeiras, educacionais e outras. (GUEDES, 1998, p. 26).}

Tal afirmação continua a encontrar ressonância no cenário contemporâneo mesmo após pouco mais de quinze anos de sua publicação, pois essas mesmas barreiras marcam o espaço web informacional. Afinal, é necessário compreender que apesar das inúmeras inciativas de politicas de inclusão, mesmo onde há acesso à internet, estas não necessariamente representam equidade socioeconômica, de acesso à informação e de suas respectivas competências por parte dos atores sociais envolvidos. Por outro lado, é correto considerarmos que o acesso à internet é um potencial sinal de desenvolvimento assim como as tecnologias de informação e comunicação (TIC) representam uma instituição social (LOPES, 2007) dado seu papel indelével no mundo atual. Ainda assim, seu emprego no tecido social é extremamente complexo e dicotômico.

As TIC, lembremos bem, se tornam produto de consumo frente o cenário capitalista contemporâneo. Seus respectivos investimentos requerem a participação direta e indireta pública e privada. Seu emprego na sociedade de forma democrática e inclusiva precisa atender 
às agendas da política de ciência e tecnologia, comunicação, social e educacional. Não é simples e tão pouco isenta de novos processos intestinos de readequação ao próprio status quo no qual se ergueram outrora os abismos sociais que nos levaram de início ao cenário de exclusão polissêmico o qual conhecemos. Basta olhar para o promissor e "libertário" terreno das startups e demais empresas ligadas à produção de apps e softwares. A medida que vão sendo criados, são em seguida adquiridos por empresas maiores que já dominam o mercado. O cenário, portanto, muda mas tende a buscar a própria manutenção de seus status quo.

Ou seja, apesar do fenômeno da internet certamente possibilitar que grosso modo algumas fronteiras, principalmente as espaciais, se rompessem; é evidente que outras apenas tenham diminuído ou adquirido características de maior maleabilidade em decorrência de uma sociedade cada vez mais integrada pela tecnologia e seu respectivo mercado onde novos bens de consumo surgem com intensidade inequívoca.

Nos últimos anos empresas como Google - hoje conhecida como Alphabet - e Facebook destacaram-se no cenário econômico entre as "top 10" adquirentes de empresas de tecnologia, responsáveis pelo desenvolvimento de softwares ou soluções em comunicação, internet, armazenamento ou rede, entre outros serviços. Apesar disso, em considerando que Chicago e Nova York já despontam como lugares de referência para tais negócios, o Vale do Silício ainda lidera o ranking como localidade cuja maioria dos negócios relacionados às empresas envolvidas é realizado. Um claro sinal de que o surgimento de softwares e "apps", além de redes sociais e outros sítios prestadores de serviço cujos consumidores fazem uso no espaço virtual reificam em lugares já historicamente reconhecidos nesse contexto a concentração física e simbólica dos capitais envolvidos.

\section{RESSONÂNCIAS POLÍTICAS E SOCIAIS DOS ESPAÇOS WEB INFORMACIONAIS}

$\mathrm{Na}$ seção anterior apontamos que a estrutura física que nos suporta a internet é reflexo de formas de dominação já conhecidas, associando-a à perspectiva de Milton Santos. Não obstante, o acesso à internet é por si só produto de uma práxis historicamente reificada na sociedade contemporânea apesar de que o cenário global nos apresente inúmeras dissonâncias a esse quadro. E que, por fim, se a estrutura física e política reforçam velhos arcabouços socioeconômicos, não seria diferente quando nos voltamos para as dinâmicas circunscritas aos territórios da internet onde produtos, informação e conhecimento continuam a ser catalisados por corporações que reproduzem o mesmo "velho jogo" no ciberespaço.

Nesta seção tentaremos ser mais incisivos no tocante aos elementos presentes no aspecto político e social dos espaços web informacionais com o objetivo de apontar alguns paradoxos e sua relação com maneira como tais espaços se configuram.

Na tentativa de construção de uma via de contramão para tal afirmação de que a exclusão digital ainda reflete uma condição dominadora e excludente de um cenário socioeconômico já conhecido, surgem iniciativas que ao primeiro contato podem parecer não apenas inovadoras como eficientes para a diminuição de tal gap ao acesso à informação de/com qualidade. Recentemente no cenário brasileiro a presidência da República anunciou parceria com a empresa Facebook para levar "conexão de banda larga a populações de baixa renda e a áreas isoladas do país, entre as quais a Amazônia e partes do Centro-Oeste" (BBC, 2015). Absoluta ingenuidade crer que tal iniciativa não traga problemas importantes à reboque da condição de "gratuidade" de acesso à internet a ser oferecida.

Afinal, é possível identificar no Facebook, por exemplo, uma completa práxis da vigilância na qual a captura de dados pessoais de usuários da rede para geração de informações a serviço de um mercado (EVANGELISTA, 2015) e potencial uso de órgãos de segurança pública. Ou seja, oferece-se o acesso ao espaço web informacional, a internet, no qual o usuário poderá navegar, mas sem lhe "traduzir" as regras do "jogo" que regem o território em questão. Aliás, questão esta de poder sobre o espaço (ainda que digital) que por sua vez afeta outro espaço, o social, econômico e o político do real. Um interfere no outro em um processo comum e recíproco. Uma política do simulacro se faz presente.

O território são formas, mas o território são objetos e ações, sinônimo de espaço humano, espaço habitado. Mesmo a 
análise da fluidez [...] passa por aí. De um lado temos uma fluidez virtual, oferecida por objetos criados para facilitar essa fluidez e que são, cada vez mais, objetos técnicos. Mas os objetos não nos dão senão uma fluidez virtual, porque a real vem das ações humanas, que são cada vez mais ações informadas, ações normatizadas. (SANTOS, 1998, p. 16).

Nada novo no tocante às formas com as quais a disputa, acompanhada de sua consequente manutenção, pelo poder opera os elementos, atores e espaços do mundo sócio-técnico. Os meios de comunicação e informação configuramse como "objetos técnicos" que operam em/no "conjunto técnico" (SIMONDON, 1989) da internet e do ciberespaço; estes, contudo são fruto de um processo convergente de "operações intelectuais, técnicas, materiais, sociais e políticas" (SANTOS, 2006, p. 143) que são por si só microcosmos de disputa e, portanto, de poder.

Nesse sentido, a parceria entre o Estado e a empresa privada Facebook pode efetivamente ir de encontro à liberdade de navegação, ao menos esperada, da qual qualquer internauta deveria dispor. Ao prover acesso à internet via Facebook, estaria-se construindo uma espécie de "celeiro" onde a população dessas regiões apenas navegaria no ciberespaço permitido, ou visível/ acessível, pelo Facebook.

A questão da visibilidade se torna importantíssima para tal debate. Afinal já se sabe que o que nos é visível na internet é fruto de um algoritmo alimentado por dados nossos e sobre nós. No caso dos motores de busca, por exemplo, o que nos é visível nada mais é que resultado de uma "dobra" (DELEUZE, 1991; MONTEIRO; FIDÊNCIO, 2013), neste caso produzida no contexto de uma "tecnopolítica do algorítimo" que dá sentido aos dados, gerando informação para quem consulta tais mecanismos tendo como elemento central para seu sucesso a "relevância" (SARACEVIC, 2015). Tal noção de relevância, no entanto tão "humana" como o próprio autor afirma, acaba por ser objetivada pela mesma "tecnopolítica do algorítimo"; à serviço das corporações atuantes na área da tecnologias de informação (TI) cujos seus proprietários representam a continuidade do sistema capitalista e de sua dinâmica acumulativa.

Neste caso a "dobra" é possível por meio da infraestrutura de indexação, classificação e localização daquilo que está na web por motores de busca como o Google ou Bing, ou ainda DuckDuck Go. Segundo Cendón (2001) em 2000 o Google indexava cerca de $56 \%$ do conteúdo do ciberespaço. Este número, no entanto, parece ser mais uma estimativa que um dado concreto pois como estipular tal porcentagem em referencia aquilo que não é indexável, localizável e portanto mensurável?

$O$ fato é que a parcela mínima do ciberespaço a qual temos acesso já está se setorizando cada vez mais. E no caso da parceria o Estado Brasileiro com o Facebook o que está se delineando é uma forma de controle e vigilância do acesso à informação e também do que se produz em lugares como redes sociais, entre outros; mas, sobretudo da forma como nos relacionamos e construímos nossa percepção de si frente um espaço de interação social completamente novo, mas nem por isso sem dono.

Aproveitando-se dos volumosos recursos ganhos com a formação de perfis de comportamento e consumo para a publicidade, o Facebook agora quer concentrar ainda mais o tráfego da web. $\mathrm{O}$ acordo do Facebook com as operadoras de telefonia tem sido questionado por colocar em risco a neutralidade da rede. Caso a operadora dê prioridade de tráfego para qualquer empresa, ela estará violando a neutralidade por motivos comerciais, estará criando uma via de alta velocidade para quem paga mais. Todavia, mesmo que não exista consenso sobre a violação da neutralidade, a prática do Facebook é de domínio da rede pelo seu grande poder econômico. Sem tragar a web para o interior de suas muralhas, o Facebook já é a segunda audiência da internet no mundo. Com o zero rating em países pobres, o Facebook pretende trazer inúmeros serviços e conteúdos hoje disponíveis na web para dentro de sua plataforma. Essa concentração dará mais acesso à sua rede, o que trará ainda mais poder econômico para a corporação de Zuckerberg. (AMADEU, 2015).

De fato, se pudermos retornar ao caso dos cabos submarinos já expostos aqui, é evidente que os meios de produção tornaram-se mais e mais devedores das estruturas informacionais enquanto estas, por sua vez, redefiniram a topografia do mercado financeiro. Dessa forma, podemos afirmar que tais estruturas e sistemas de subordinações não são, no entanto, novas em sua essência apesar de apontarem inovações quanto à forma que se desenvolvem. 
Há, portanto, um paradoxismo para os estudos do ciberespaço pelo campo da Ciência da Informação $(\mathrm{CI})$, pois como já disse Santos: "é o uso do território, e não o território em si mesmo" (1998, p. 15) que o torna objeto das análises sociais uma vez que seria o seu uso o verdadeiro fenômeno social, dinâmico, "entalhado" pelas lutas de classe anteriores e advindas de tais usos. Outrossim, enquanto meio técnico-científico e informacional, os sítios, as redes sociais, os softwares e seus diferentes aplicativos, tornaram-se detentores de um capital social sem precedentes. Nele está a informação que por sua vez é capital na Era Digital. A CI não pode apenas estudar os meios informacionais e sua aplicabilidade técnica. A produção e o controle, o uso e o consumo destes meios devem ser igualmente alvo de sua reflexão.

É mister que a topografia do ciberespaço é extensa em termos horizontais e verticais; sendo possível considerar que suas dimensões e dinâmicas info-comunicacionais afetam não somente a cultura, e a relação com a memória, mas a forma como construímos nosso conhecimento e arcabouço informacional para o futuro (SARLO, 2007); afetando direta e indiretamente as formas de produção e circulação do conhecimento (SARACEVIC, 1996).

Nele há espaços concêntricos, seccionados entre si, multicamadas, convergentes, restritos e desconexos. Todos os dias, bilhões de indivíduos, mesmo que clivados por suas diferenças culturais e econômicas, navegam no ciberespaço por meio da internet. Ela é, tão somente, o meio, a via e o sentido arquitetado por aqueles que criaram os protocolos de navegabilidade na web. Tim Berners-Lee, criador do protocolo de transferência de hipertexto (HTTP) operacionalizou tal sistema como hoje o conhecemos. Em grande parte dos acessos à internet, usamos o protocolo criado por BernersLee, como uma espécie de "cartografia" comum para nos deslocarmos por este espaço digital.

Espaço que é constantemente sobreposto a si mesmo. Dobra-se em si a partir de hiperlinks e convergências de plataformas. Fóruns, sites de compras e reclamações de serviços igualmente oferecidos na web, blogs, redes sociais diversas e portais jornalísticos entre outros tantos exemplos, mesmo quando restringidos por um domínio privado e fechado, possuem os meios capazes de transversalizar domínios, redes, plataformas, interfaces, linguagens e softwares.
Assim a informação circula e se torna acessível para a maior parte dos usuários da internet que se mantêm capazes de acessar e transitar pela nova "cartografia dos protocolos de informação e comunicação".

Em complemento, o advento do ciberespaço seguido da internet enquanto espaço informacional público e privado digital onde redes sociais, estabelecimentos comerciais, prestação de serviços e páginas pessoais e institucionais se estabelecem e atuam no mundo social, econômico, político e cultural, apenas tornou possível a reprodução dos sistemas já existentes. Em verdade, a internet é produto de uma arquitetura informacional de macroescala cujo meio técnico-científico-informacional (SANTOS, 2006) se tornou o simulacro das respectivas práticas hodiernas.

Paradoxalmente, este mesmo simulacro acabou por favorecer uma maior exposição de questões ligadas à identidade e de ações coletivas e individuais advindas das práticas de comunicação uma vez que o artificial se naturalizou (SANTOS, 1988, p. 16). Daí também compreende-se a possibilidade do simulacro. O espaço do homem [...] vai tornando-se um espaço cada vez mais instrumentalizado, culturizado, tecnificado e cada vez mais trabalhado segundo os ditames da ciência (SANTOS, 1988, p. 16).

É este espaço que dita as regras aos seus "atuantes, passantes, navegantes, informantes". Culturiza e tecniciza da mesma forma que politiza e produz/induz a reminiscências sobre o que não é nosso, mas pode tornar a ser. A internet é um simulacro capaz de todas essas ações, além de tantas outras.

\begin{abstract}
O território já não precede o mapa, nem lhe sobrevive. É agora o mapa que precede o território - precessão de simulacros - é ele que engendra o território cujos fragmentos apodrecem lentamente sobre a extensão do mapa. (BAUDRILLARD, I99।, p. 8).
\end{abstract}

\section{CONSIDERAÇÕES FINAIS}

Com base no que tratamos até este momento, podemos afirmar que há uma artificialidade que confere realidade ao espaço digital. Espaço este que, conforme proposto por Santos (2006, p. 39) nada mais é que um 
"sistema de objetos", artificiais, que se mistura a um "sistema de ações" também plenas em artificialidade mas que compõem a nossa "cultura de visibilidade" informacional e as políticas em torno e transversas a ela.

Nesse sentido, concluímos que a artificialidade dos objetos que compõem o espaço é crescente e evidente. Dependemos dos relógios, dos smartphones, de seus aplicativos, sobretudo da informação que é mediada por eles, e softwares algumas vezes criados por um adolescente ordinário que ganham o mercado mundial, tablets, life logging objetcs, wearable Technologies, e-books, ultrabooks, notebooks, entre outros tantos, para continuarmos conectados. Conectados a que? A quem? E como? A artificialidade desses objetos técnicos nos permite viver em uma configuração de mundo cada vez mais naturalizada e naturalizante.

Santos (2006, p.145) ainda aponta sua concordância às proposições feitas por Simondon (1989) quando o mesmo diz ser os objetos técnicos mais perfeitos que a natureza uma vez que são projetados, desenhados, disponibilizados para um determinado fim.

Foi, portanto, que consideramos neste cenário o locus onde se identifica a cultura informacional atual, presente na hipermodernidade (LIPOVETSKY; CHARLES, 2004), e seus respectivos dispositivos (DELEUZE, 1991; 1999) (FOUCAULT, 1984; 1990; 2000), responsáveis pela forma como concebemos nossa relação com os aspectos comunicativos e informacionais nas quais questões relacionadas à ideia de visibilidade, de memória e de vigilância no século XXI ganham corpo.

O exercício de reflexão sobre o ciberespaço e seus territórios, que aqui intitulamos como web espaços informacionais, requereu que o compreendêssemos enquanto espaço-produto da interação do homem com seus dispositivos técnicos e político-culturais. E que, marcados por suas "rugosidades" características compõem uma "cultura da visibilidade" ambivalente onde ao mesmo tempo em que se busca ser visto, tentase igualmente vencer o grande desafio que é o de se preservar a privacidade. Ambos os pleitos que nos conduzem a situações cada vez mais comuns pari passu o desenvolvimento igualmente intenso das práticas e tecnologias viabilizadoras de transparência, de acesso e de recuperação da informação na internet.
Neste sentido, entre "o ver", "o ser" e "o saber", consideramos tecnopolíticos aspectos como: (1) o do acesso à informação, (2) aquele relacionado às identidades e (3) da produção do conhecimento na era digital. Nestes, é possível perceber que: (1) implica tanto atores responsáveis por disponibilizar a informação de forma acessível como aqueles com competência para acessar a mesma; além de ser dependente de dispositivos legais, jurídicos e tecnológicos para garantir sua manutenção no espaço público democrático; (2) constituem-se a partir de um cenário tecnológico referencial às constantes manutenções e reconfigurações das identidades, alavancado pela crescente velocidade e heterogeneidade presentes nos meios infocomunicacionais da era digital; estas identidades não são estáticas e se encontram, portanto em um contínuo processo de "individuação" (SIMONDON, 1989); (3) contínuo devido aos elementos/agentes que interferem e definem diretamente a "paisagem" na qual se dá o processo de produção do conhecimento na contemporaneidade.

Importante frisar que tais mudanças não alteraram a essência das forças constitutivas das técnicas e de seus respectivos espaços de atuação e reprodução. De fato, estas mudanças são a representação de um processo de "concretização" dessas mesmas formas de atuação e reprodução.

São elas apropriadas "de um modo específico pelo espaço preexistente" (SANTOS, 2006, p. 23), se considerarmos aqui o ciberespaço e a internet, as técnicas e seus saberes, não escapam por completo do processo sóciohistórico, cultural e econômico; mas não deixam de estabelecer novas práticas e novas ações em torno das dinâmicas ora instituídas. Ou seja, encontramos no universo das práticas de comunicação um processo de "concretização" (SIMONDON, 1989, p. 219), do qual se compreende aí um processo histórico, cujas técnicas desenvolvidas e aplicadas são hoje tão ou mais enraizadas em uma cultura tecnológica informacional do que as formas mais simples, basilares.

Vale lembrar que, quando pensamos nos atores que ocupam de inúmeras maneiras os espaços aqui em jogo, seus processos de concretização se dão pelo que Simondon (1989) chama de "individuação". É a partir daí, ou partindo dessa perspectiva, que podemos 
compreender atualmente como discutir questões ligadas grosso modo à reconfiguração de identidades a partir das experiências atuais e dos novos desafios no campo político da técnica, da informação e do consumo.

Algumas dessas experiências nos conduzem a refletir sobre a hermeticidade de algumas redes sociais. Somente acessível aos seus participantes após criação e perfil e concordância com o termo de reponsabilidade, dois elementos comuns para a maioria de usuários dessas redes, este espaço é completamente vigiado com o objetivo de catalisar preferências, tendências e perfis de consumidores em perspectiva transnacional. Em algumas destas redes, o facebook pode ser o exemplo mais conhecido no momento, seu usurário se torna "curador" de si ao selecionar e expor gostos, humores, imagens que aparentemente "o define", vídeos e textos de sua preferencia. É obvio que os usuários não expõem na "vitrine" de suas timelines informações apenas para seus contatos.

$O$ que produzem, direciona-se em um grande fluxo de dados aos data centers das redes sociais em um movimento sem precedentes de extração de uma nova matéria prima: a informação.

Artigo recebido em 14/03/2016 e aceito para publicação em II/07/2016

\title{
ROUGHNESS OF CYBERSPACE: $a$ theoretical contribution to the study of web information spaces
}

\begin{abstract}
This article presents a contribution to the area of Information Science, in its theoretical dimension by working concepts of the geographer Milton Santos as guiding elements for an analysis of the physical and technological infrastructure that make up what we call as web-informational spaces. also marked in concepts of the philosopher Gilbert Simondon, aims to identify the structures and technical objects that make up these spaces in its implementation process, recognizing these same, recurring practices of a global scenario marked by the concentration of capital and technological scientific knowledge. The article opens with this, the proposition that the forms of visibility and information access the web information spaces are a priori as roughness of an existing structure despite the innovations made to objects, platforms and information systems in constant development.
\end{abstract}

Keywords: Cyberspace. Internet. Information. Rugosity. Milton Santos.

\section{REFERÊNCIAS}

AMADEU, S. Acordo Dilma-Zuckerberg concentra o tráfego da rede e pode violar Marco Civil. Disponível em: <http://www. brasilpost.com.br/sergio-amadeu/acordodilmazuckerberg-co_b_7057276.html>. Acesso em: 13 jun. 2015.

BBC. Dilma anuncia parceria com Facebook para ampliar acesso à internet. BBC Brasil [webpage]. Disponível em: <http://www.bbc.com/ portuguese/noticias/2015/04/150410_dilma_ facebook_pai_jf $>$. Acesso em: 10 abr. 2015.

BEY, H. TAZ, Zona Autônoma Temporária. São Paulo: Conrad Editora do Brasil, 2001.
BRAMAN, S. The Emergent Global Information Policy Regime. Houndsmills, UK: Palgrave Macmillan, 2004.

BAUDRILLARD, J. Simulacros e simulação. Lisboa: Relógio d'água, 1991.

CENDÓN, B. V. Ferramentas de busca na Web. Ci. Inf. , Brasília, v. 30, n. 1, 2001. Disponível em: $\quad<$ http://revista.ibict.br/ciinf/article/ view/937/974>. Acesso em: 13 jan. 2016.

CORTEZ, A. T. C., ORTIGOZA, S. A. G. (orgs.). Da produção ao consumo: impactos socioambientais no espaço urbano [online]. São Paulo: Editora UNESP; São Paulo: Cultura Acadêmica, 2009. Disponível em: <http:/ / books.scielo.org>. Acesso em: 24 mar. 2016. 
DELEUZE, G. Que és un dispositivo? In: BALIBAR, E.; DREYFUS, H.; DELEUZE, G. et al. Michel Foucault, Filósofo. Barcelona: Gedisa, 1999. p. 155-163.

DELEUZE, G. A dobra: Leibniz e o barroco. Campinas: Papirus, 1991.

EVANGELISTA, R. Na Era da discriminação digital. Carta Capital, 03 jun. 2015. Disponível em: <http://www.cartacapital.com.br/blogs/ outras-palavras / na-era-da-discriminacaodigital-2508.html>. Acesso em: 03 jun. 2016.

FOUCAULT, M. Microfísica do poder. Rio de Janeiro: Graal, 2000.

Tecnologias del yo y otros textos afines.

Barcelona: Paidós, 1990.

História da sexualidade II. O uso dos prazeres. Rio de Janeiro: Graal, 1984.

FREIRE, I. M. Acesso à informação e identidade cultural: entre o global e o local. Ci. Inf., Brasília, v. 35, n. 2, p. 58-67, ago. 2006 . Disponível em: <http://www.scielo.br/ scielo.php? script $=$ sci arttext\&pid=S0100-19652006000200007\&lng=en\& nrm=iso >. Acesso em: 16 jan. 2016.

GONZÁlEZ DE GÓMEZ, M. N. Regime de informação: construção de um conceito. Informação e Sociedade, v. 22, n. 3, p. 4360, set./dez. 2012. Disponível em: <http:// www.ies.ufpb.br/ojs/index.php/ies/article/ view/14376/8576>. Acesso em: 01 out. 2015.

GUEDES, O. As novas tecnologias de comunicação e informação: novos mecanismos de exclusão social? Perspect. Cienc. Inf., Belo Horizonte, v.3, n.1, p. 21-26, jan./jun. 1998. Disponível em: <http://portaldeperiodicos.eci. ufmg.br/index.php/pci/article/view/607/376>. Acesso em: 17 fev. 2016.

HUGUES, T. P. Networks of power, eletrification of western society. Baltimore/London: John Hopkins University Press, 1980.

ITU, International Telecommunication Union. Global broadband growth slows sharply: 4 billion still off-line [press release], 21 set. 2015. Disponível em: <http://www.itu.int/net / pressoffice/press_releases/2015/35.aspx\#. VhKAibRVikp>. Acesso em: 05 out. 2015.

JEANNERET, Y. La relation entre médiationet usage dans les recherches en informationcommunication. In: Actes du Colloque Médiations et Usages des Savoirs et de L'information: Un Dialogue France-Brésil (Reseaux Mussi). Rio de Janeiro: Instituto de Comunicação e Informação Cientifica e tecnológica em Saúde/FIOCRUZ, 2008. p.37-59.

JOERGES, B. Large technical systems: concepts and issues. In: MAYNTZ, Renate; HUGHES, Thomas P. (eds.) The development of large technical systems. Frankfurt: Campus, 1988. p. 9-36.

LAZZARIN, F. A.; AZEVEDO NETTO, C. X.; SOUSA, M. R. F. Informação, memória e ciberespaço: considerações preliminares no campo da ciência da informação. Transinformação, v. 27, n.1, 2015. Disponível em: <http://periodicos.puc-campinas.edu.br /seer/ index.php/transinfo/article/view/2672/1912>. Acesso em: 18 set. 2015.

LÉVY, P. A inteligência coletiva: por uma antropologia do ciberespaço. São Paulo: Loyola, 2003.

LIPOVETSKY, G. A felicidade paradoxal: ensaio sobre a sociedade do hiperconsumo. São Paulo: Cia. das Letras, 2007.

LIPOVETSKY, G.; CHARLES, S. Os Tempos Hipermodernos. São Paulo: Barcarolla, 2004.

LOPES, C. A. Exclusão Digital e a Política de Inclusão Digital no Brasil - o que temos feito? Revista de Economía Política de las Tecnologías de la Información y Comunicación. vol. IX, n. 2, mayo-ago. / 2007. Disponível em: <http:// www.seer.ufs.br/index.php/eptic/ article/ viewFile/235/230>. Acesso em: 16 jan. 2016.

LOPES, R. S. Informação, conhecimento e valor. São Paulo: Radical Livros, 2008. 
MARQUES, R. M. Trabalho, informação e conhecimento: relendo Marx na era da informação. LOGEION: Filosofia da informação, Rio de Janeiro, v. 2, n. 1, p.47-71, set. 2015/fev. 2016. Disponível em: <http://revista.ibict.br/ fiinf/article/view/1476/1654>. Acesso em: 15 mai. 2016.

MCLUHAN, M. Understanding media: the extensions of man. [Edited by W. Terrence Gordon - Critical Ed.] Berkeley, CA: Gingko Press, 2011.

MONTEIRO, S. D. O ciberespaço: o termo, a definição e o conceito. DataGramaZero, v. 8, n. 3, jun. 2007. Disponível em: <http:/ /www.dgz.org. br/jun07/Art_03.htm\#autores>. Acesso em: 19 set. 2014.

MONTEIRO, S. D.; FIDÊNCIO, M. V. As dobras semióticas do ciberespaço: da web visível à invisível. TransInformação, Campinas-SP, n. 25, v. 1, p. 35-46, jan./abr. 2013. Disponível em: <https://www.puc-campinas.edu.br/ periodicocientifico>. Acesso em: 28 abr. 2013.

MOUNIER, P. Os donos da rede: as tramas políticas da internet. São Paulo: Loyola, 2006.

PINHEIRO, M. M. K. Estado informacional: implicações para as políticas de informação e inteligência no limiar do século XXI. Varia História, v. 28, n.47, jan/jun. 2012. Disponível em: <http://www.scielo.br/pdf/vh/v28n47/04. pdf $>$. Acesso em: 17 set. 2015.

RABAÇA, C.; BARBOSA, G. G. Dicionário de comunicação. 2. ed. rev. e atual. Rio de Janeiro: Campus, 2001.

RYAN, J. A history of the Internet and the digital future. London: Reaktion books, 2010.

SANTOS, M. Por uma outra globalização: do pensamento único a consciência universal. 19a Ed; Rio de Janeiro: Record, 2010.

SANTOS, M. A natureza do espaço: técnica e tempo, razão e emoção. [col. Milton Santos] São Paulo: EdUSP, 2006.
SANTOS, M. "O retorno do território". In.: SANTOS, M.; SOUZA, M. A. A.; SILVEIRA, M. L. (orgs.) Território, globalização e fragmentação. [4. ed.] Campinas: Hucitec, 1998. p. 15-20.

SANTOS, M. Metamorfoses do espaço habitado: fundamentos teóricos e metodológicos da geografia. São Paulo: Hucitec, 1988.

SARACEVIC, T. Ciência da Informação: origem, evolução e relações. Perspec. Ci. Inf., v.1, n.1, p.41-62, jan./jun.1996. Disponível em: <http:// portaldeperiodicos.eci.ufmg.br/index. php/pci/ article/view/235/22>. Acesso em: 12 fev. 2016.

Why is relevance still the basic notion in information science? (Despite great advances in information technology). International Symposium on Information Science (ISI 2015). Zadar, Croatia. may. 18-21, 2015. Disponível em: $<$ https://comminfo.rutgers.edu / tefko/articles. htm>. Acesso em: 12 jan. 2016.

SARLO, B. Tempo passado: cultura da memória e guinada subjetiva. São Paulo: Cia das Letras; Belo Horizonte: UFMG, 2007.

SILVA, A. M. Inclusão Digital e Literacia Informacional em Ciência da Informação. Prisma.com, n. 7: 16-43, 2008. Disponível em: <http://repositorioaberto.up.pt/bitstream/ 10216/25490/2/ armandomalheiroinclusao000101504.pdf $>$. Acesso em: 05 out. 2015.

SIMONDON, G. Du mode d'existence des objets techniques. 3. ed. Paris: Aubier, 1989.

TODARO, M.; SMITH, S. C. Economic Development. 11. ed. Pearson Education Limited: 2012.

UN FOUNDATION. Achieving universal energy access. United Nations Foundation. [webpage]. 2013. Disponível em: <http:// www.unfoundation.org/what-we-do/issues/ energy-and-climate/clean-energy-development. html?referrer=https:/ / www.google.com.br/ > . Acesso em: 20 jan. 2016. 